\title{
U.S. NATIONAL SCIENCE FOUNDATION SUPPORT FOR THE DISSEMINATION OF SCIENTIFIC INFORMATION
}

\begin{abstract}
A PAMPHLET on the dissemination of scientific information, issued by the National Science Foundation*, outlines the Foundation's programmes to discharge the responsibilities for interchange of scientific information and support of the dissemination of such knowledge placed on it by the Congress Act of 1950, and extended in 1958 by directives from the Congress and from the President. An Act of 1958 also established a Science Information Council to be an advisory group to the Foundation's Office of Science Information Service. The Foundation's programmes have two fundamental objectives: promotion of newer and better techniques for handling and dissemin. ating scientific information, and making existing systems more effective. Its scientific information activities are carried out under five programmes organized in two Sections: the Studies and Support Section, which includes programmes of basic studies, improved processes and systems and support of communication; and the Science Information Co-ordination Section, which includes programmes of Federal science information and of the domestic and foreign science information.

Under the first section, support is provided for research development, experimental application and evaluation of systems of information retrieval, mechanical translations, libraries and publications, with the principal emphasis on improving basic understanding of general problems rather than on establishing particular systems. The Foundation continues to support long-range research on systems for the automatic processing of natural language text with the
\end{abstract}

* Nacional Science Foundation. Programs for Improving the Dissemination of Scientific Information. (NSF-64-22.) Pp. 15. (Washington, D.C.: National Science Foundation, 1964.) eventual aim of mechanizing procedures for indexing, abstracting, organizing and storing information. Research in mechanical translation is a part of this broader field, while, in the work on publication systems, projects have been undertaken to analyse the part played by computers in scientific publication and to investigate machine recording of textual information during the publication of scientific periodicals.

As part of the Foundation's general programme for strengthening the science library network of the country, the information systems programme is seeking ways to improve the effectiveness of those libraries which provide substantial science information services. The publication support programme provides support for journals publishing results of original research, as well as temporary financial assistance for the cover-to-cover and selective translation of research published in Russian, Japanese and Chinese. Any publication considered favourably for support must be making, or showing good promise of making, a significant contribution to the scientific research literature; moreover, its proposed mechanics of publication must be efficient and economically sound.

The principal interests of the programmes for science information co-ordination are to promote non-Federal science information activities in the United States and to co-ordinate these with developments in foreign countries. Two major federal information centres are supported and administered. The first is the Science Information Exchange, which acts as a clearing house for information on current research, while the second is the National Referral Center for Science and Technology, located at the Library of Congress.

\section{RESEARCH ON SHELTER IN AGRICULTURE AND HORTICULTURE}

\begin{abstract}
THE effects of exposure to wind are of direct concern to agriculture, horticulture and forestry, and the practice of using shelterbelts and non-living windbreaks to reduce local levels of wind is of long standing. The broad picture of reduced windiness, altered microclimatic conditions and improved production of crops in the vicinity of windbreaks is generally established; the detailed analysis of these influences is, however, still incomplete. Research into the effects of shelter on microclimate and crop yields began in the early years of this century in a few countries, gained momentum in the United States and U.S.S.R. during the 1930 's and, after 1945 , attracted much wider interest and support. Early research was concentrated on determining the most suitable type of windbreak for a particular situation and providing a local measure of the benefit likely to be derived from shelter. More recently, it has become necessary for a more fundamental approach to the understanding of the nature and value of shelter: better definition of the physical environment near the ground arising as a result of shelter, and of the relationships between environment and biological processes in both crops and animals. Consequently, it is appreciated that further developments in the field of shelter research must be reviewed periodically in the light of developments in other environmental studies such as agronomy, ecology, micrometeorology, plant and animal physiology and nutrition.

In order to provide for closer communication between research workers in the various fields relevant to the ques.
\end{abstract}

tion of shelter, the Ministry of Agriculture, Fisheries and Food, through its Shelter Research Planning Group (now Shelter Research Committee), arranged a first symposium on shelter research at Aberystwyth in 1962 (Nature, 194, $1130 ; 1962)$. The success of this venture led to a second symposium arranged in co-operation with the Department of Agriculture and Fisheries for Scotland and held at Edinburgh on September 15-16, 1964.

In the second symposium, sessions were again divided between horticultural and field crop aspects of shelter, meteorological developments associated with shelter, and shelter in relation to livestock. In a paper on wind speed and plant growth, Dr. R. M. Wadsworth (Un:versity of Reading) dealt with the effect of wind on plant environment and on plant growth as measured by such parameters as relative growth rate, net assimilation rate and leaf-area ratio. Laboratory experiments under controlled wind conditions have suggested that the optimum wind speed for plant growth varies according to other environmental conditions, being between 0.5 and $3 \mathrm{~m} / \mathrm{sec}$ for very favourable conditions and lower for less favourable conditions. Since wind affects growth to a greater extent when plants are isolated, windbreaks may be more essential in the early life of a crop than later. Low light intensities may also suggest a greater need for wind reduction, whereas light winds are likely to prove increasingly beneficial as light intensity increases in order to prevent reduction in $\mathrm{CO}_{2}$ availability. 